\title{
Ocular Complications of Type 1 Diabetes
}

\author{
Daniel Rappoport, Yoel Greenwald, Ayala Pollack and Guy Kleinmann \\ Ophthalmology Department, Kaplan Medical Center, POB 1, Rehovot,
}

Israel

\section{Introduction}

Type 1 diabetes is a complex metabolic disease involving multiple organ systems which may cause severe visual impairment. Almost all parts of the eye may be affected including: the extra-ocular muscles, intra-ocular lens, the optic nerve, and retina.

Diabetes is the leading cause of blindness between the ages of 20 and 74 in many developed countries (Cheung et al., 2010; Powers, 2008). Individuals with diabetes are 25 times more likely to become legally blind than individuals without diabetes. Blindness is primarily the result of diabetic retinopathy that accounts for $1 / 4$ of blind registrations in the western world (Cheung et al., 2010; Powers, 2008).

Prevention of severe visual impairment in type 1 diabetes includes: optimal glycemic control, the treatment of ancillary risk factors such as hypertension, regular ophthalmic screening, and early diagnosis and treatment of ocular complications.

In the following chapter we will describe the ocular complications of diabetes and the treatments for these conditions.

\section{Extra-ocular muscles}

Diabetics may present with a sudden onset of diplopia (double vision). This is usually caused by the partial or complete paralysis of one of the extra-ocular muscles due to microvascular damage to the third, fourth or sixth cranial nerve (Thomas \& Graham, 2008; Kline et al. 2010).

When a third cranial nerve palsy occurs, it is important to differentiate between a diabetic nerve palsy and paresis due to compression of the nerve from an aneurysm at the junction of the posterior communicating and internal carotid arteries. In diabetic nerve palsy the pupil is often spared meaning that it continues to react to light appropriately despite damage to the motor capabilities of the third cranial nerve. Typically in cranial nerve palsy due to a space occupying lesion such as an aneurysm, the pupil in the affected eye is dilated. In $20 \%$ of patients with diabetic nerve palsy there may be pupil involvement, however this is usually a mild efferent defect (Kline et al. 2010). Aneurysms are rare in children but may be present in adolescents, so ruling it out, by neuroimaging, is crucial. Pain may also be present in diabetic third nerve palsy. When there is paresis of the fourth or sixth cranial nerve, referral to a neuro-ophthalmolgist is also recommended for follow-up and to exclude other causes, such as myasthenia gravis or brain lesions. 
When the oculomotor defect is due to microvascular complications of diabetes the prognosis is good.

Recovery of ocular motor function generally begins within three months of onset and recovery is usually complete. Although the diplopia can be debilitating, due to the generally limited course of these complaints, patients can usually be effectively managed conservatively with eye patching. Surgery is rarely indicated.

\section{Lens: Cataract and refractive changes}

Hyperglycemia can reduce lens clarity. Hyperglycemia also induces changes in the refractive index and accommodative amplitude of the lens, both of which also act to reduce visual function (Flynn \& Smiddy, 2000).

\subsection{Refractive and accommodative changes}

One of the most frequently encountered ocular manifestations of diabetes is abrupt changes in the refractive power of the lens. When the blood glucose level is high, the glucose concentration in the aqueous humor, the fluid surrounding the lens, increases as well. This causes the glucose concentration in the lens to increase by diffusion (Flynn \& Smiddy, 2000). Under normal conditions glucose is metabolized inside the lens by glycolysis. However, when the glucose level in the lens is very high, glycolysis enzymes are overridden and some glucose is reduced by the enzyme aldose reductase and converted to sorbitol (Stirban et al., 2008). Sorbitol is metabolized slowly by the lens cells and accumulates, increasing the osmotic pressure inside the lens. This increased osmotic pressure leads to an influx of water from the aqueous humor and the lens swells. This larger lens is more convex and therefore more powerful at bending incoming light which alters the focal point of the eye, causing acute nearsightedness (myopia) and blurred distance vision.

These refractive changes may be up to three to four diopters and may last for several weeks. Thus, patients with poorly controlled blood glucose levels experience transient refractive changes due to fluctuating levels of glucose in the blood. Acute blurring of vision may be the first symptom of undiagnosed or poorly controlled diabetes.

Accommodation, the ability to adjust focus for near tasks such as reading, is also affected in patients with diabetes. Studies have shown that diabetics have decreased amplitude of accommodation compared to age matched controls, and require spectacle correction for near work at a younger age than non-diabetics (Flynn \& Smiddy, 2000).

\subsection{Cataract}

Cataract is a common cause of visual impairment in patients with diabetes. Epidemiological studies have revealed an up to five-fold increased prevalence of cataracts in diabetic patients. Individuals with type 1 diabetes manifested a greater prevalence of cataracts between the ages of 18 to 44 than age-matched controls (Obrosova et al., 2010). Duration of diabetes and quality of glycemic control are the major risk factors for early cataract development.

Potential mechanisms of diabetic cataract formation include accumulation of lenticular sorbitol, as described in the previous section (3.1). This reduces lens clarity leading to early cataract formation. It has also been postulated that recurrent high levels of glucose in the lens lead to the glycolation of lens proteins from increased non-enzymatic glycation and 
oxidative stress to the lens (Obrosova et al., 2010). This causes diabetic patients to develop age related lens changes similar to non-diabetic age related cataracts, except at a younger age than non-diabetics (Bobrow et al. 2010). Several studies have analyzed the effect of vitamin and anti-oxidant supplements, such as vitamin C, E and beta carotene and zinc on preventing or slowing progression of age related cataracts in diabetes without showing any statistically significant benefit with their use (AREDS report no. 9, 2001 as cited in Obrosova et al., 2010).

A rarer form of cataract in diabetics that is seldom encountered in clinical practice today is called the 'true diabetic cataract'. This is typically seen in young patients with uncontrolled diabetes. Any rapidly maturing (i.e whitening) cataract in a child or a young adult should raise awareness to the possibility of diabetes.

Cataract surgery is indicated when visual function is significantly impaired by the cataract. Surgery is also indicated if the cataract obscures the view of the retina and makes the diagnosis and treatment of diabetic retinopathy difficult. Cataract surgery is safe in diabetic patients and there is a 95\% success rate in terms of improved visual acuity (Obrosova et al., 2010). Good glycemic control, fluid and electrolyte balance should be maintained perioperatively and the patient's primary care physician and anesthesiologist should be involved. It is recommended that the surgery be scheduled in the morning to minimize changes in the patient's usual schedule (Purdy et al., 2010). Some controversy exists regarding a potential association between cataract surgery and a subsequent worsening of diabetic retinopathy. Patients should be made aware of this risk pre-operatively. Cataract surgery and its effect on diabetic retinopathy will be discussed in more detail the diabetic retinopathy section (7.6.2).

\section{Cornea}

Structural changes to the corneal basement membrane in diabetes decrease the adhesion of corneal epithelial cells to the deeper stromal tissue. This increases the risk of recurrent corneal erosions (Reidy et al., 2010). In addition, accumulation of sorbitol in the cornea during periods of hyperglycemia leads to hypoesthesia (a loss of corneal sensation). Both hypoesthesia and epithelial adhesion dysfunction occur more frequently with increased severity and duration of diabetes. In these patients, any epithelial injury, either from trauma, during ocular surgery or from routine contact lens use, may result in prolonged healing times. This increases the risk of severe complications such as bacterial infiltration and ulceration.

\section{Iris and pupil}

Bilateral tonic pupils may be seen in diabetic patients (Kline et al., 2010). This manifests with sluggish, segmented pupillary reactions to light and better response to near effort, followed by slow redilation of the pupil. Tonic pupils are caused by microvascular damage to postganglionic parasympathetic pupillomotor nerve fibers. Diminished pupillary response is also seen due to glycogen infiltration of the pigment epithelium and sphincter and dilator muscles (Thomas \& Graham, 2008).

Rubeosis iridis, neovascularization in the iris, is a serious complication of diabetes which occurs in patients with severe diabetic retinopathy (Thomas \& Graham, 2008). Growth factors released from the ischemic retina induce the development of intertwining blood 
vessels on the anterior surface of the iris (figure 1). These vessels can block the normal drainage of fluid from the anterior chamber, leading to a sharp and persistent rise in intraocular pressure. This complication is known as neovascular glaucoma. This type of glaucoma is often refractory to treatment and can be associated with pain from very high ocular pressure. Topical medical therapy used commonly in other forms of glaucoma is often less effective. Treatment should include aggressive control of the underlying retinal disease with peripheral laser ablation to reduce ischemia. The treatment of proliferative diabetic retinopathy will be discussed in more detail in section 7.6.2.3.

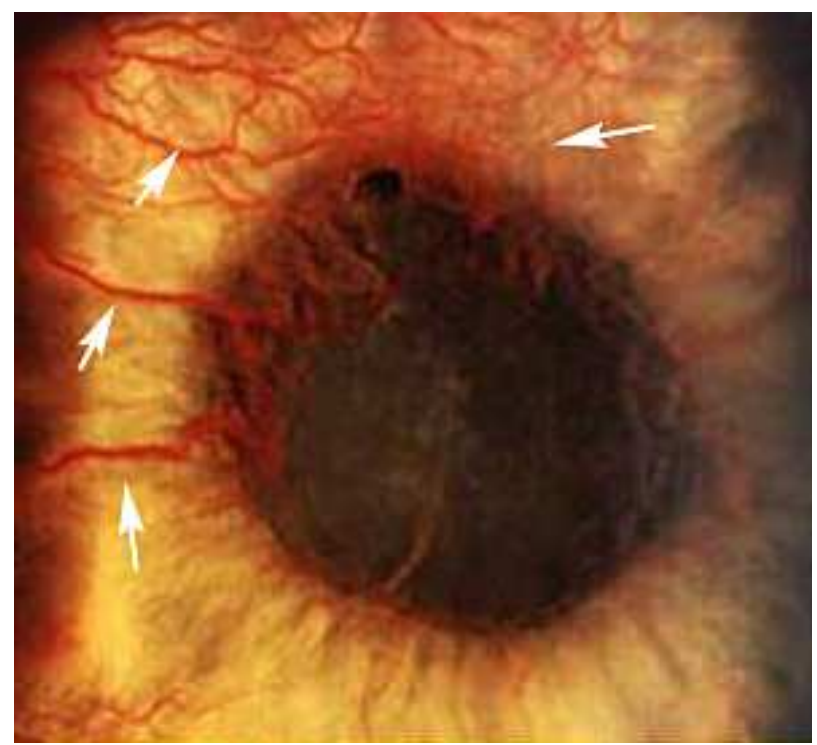

Fig. 1. Neovascularization of the Iris: These pathologic blood vessels on the iris (white arrows) are associated with retinal ischemia in proliferative diabetic retinopathy. The normal iris has no visible surface blood vessels.

\section{Optic nerve}

\subsection{Diabetic papillopathy}

In diabetic papillopathy, chronic swelling of the optic disc often associated with mild visual impairment. The suspected cause is mild reversible ischemia of the optic nerve head (Ostri et al., 2010; Kline et al., 2010). Risk factors include pronounced recent decrease in hemoglobin $A_{1 C}$ and a small cup to disc ratio of the optic nerve head. Patients often present with no visual complaints or with a mild nonspecific visual disturbance such as mild distortion or blurring. There is no pain and visual acuity is usually normal but may be slightly diminished. There is no afferent pupillary defect. An enlarged blind spot is seen on visual fields. Clinical examination reveals unilateral or bilateral hyperemic edema of the optic disc, accompanied by dilation of inner disc surface vessels, vascular leakage and axonal swelling (cotton wool spots). These enlarged vessels may be confused with neovascularization of the disc but these radially dilated vessels do not extend into the vitreous (Figure 2). 


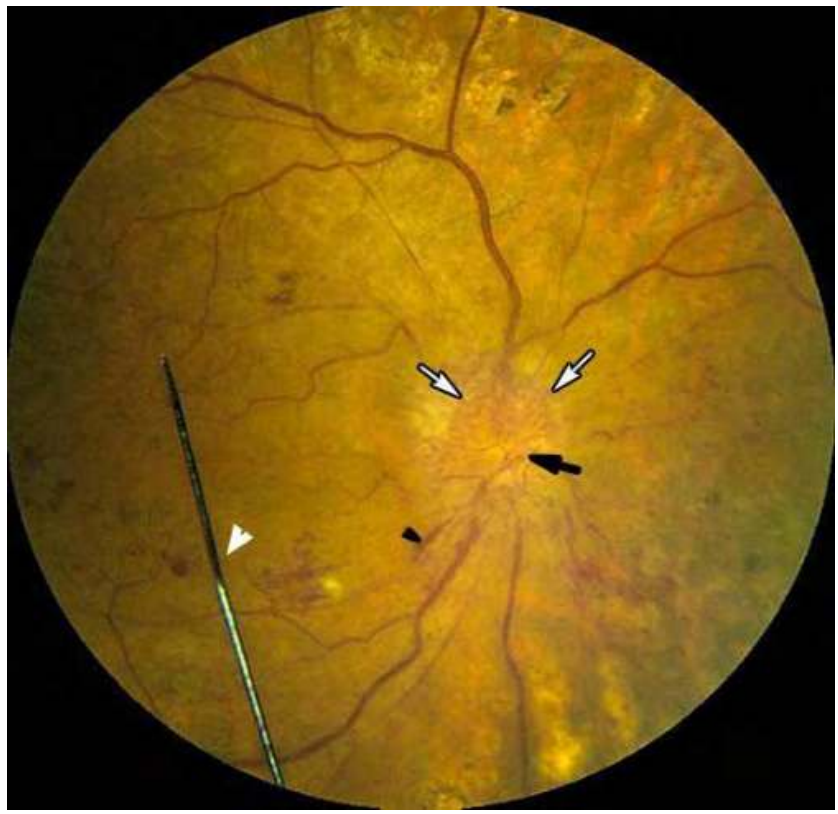

Fig. 2. Diabetic Papillopathy. A chronic swelling of the optic disc often associated with mild visual impairment. This color fundus photograph shows blurred disc margins (white arrows), flame shaped hemorrhages (black arrowhead). The dilated blood vessels on the optic disc (black arrow) may be confused with neovscularization but are radially dilated, do not enter the vitreous cavity and do not leak on fluorescein angigraphy.[ marked by the white arrowhead the pointer aiding the patient's fixation during photography].

When diabetic papillopathy is suspected, it is important to perform fluorescein angiography. In diabetic papillopathy, dye leakage is limited to the disc and peripapillary retina as opposed to the intravitreal leakage seen in the case of neovascular lesions. Diabetic retinopathy is usually present at diagnosis, but in $20 \%$ of reported cases there was no clinical evidence of any diabetic retinopathy (Kline et al., 2010). If the optic disc edema is bilateral, the initial evaluation should include brain imaging and lumbar puncture to rule out intracranial space occupying lesions and elevated intracranial pressure.

The optic disc edema resolves in many cases without treatment, usually within two to ten months. Minimal optic atrophy is seen in $20 \%$ of cases. In rare cases, especially in poorly controlled patients, diabetic papillopathy may progress to non-arteritic anterior ischemic optic neuropathy (NAION) with significant optic atrophy and arcuate visual field defects. In most cases, long term visual acuity depends on the associated diabetic retinopathy. There is no proven treatment for diabetic papillopathy.

\subsection{Non-arteritic anterior ischemic optic neuropathy (NAION)}

Non-arteritic anterior ischemic optic neuropathy (NAION) occurs as a consequence of the interruption of blood flow to the optic nerve at the level of the optic disc. NAION is characterized by diffuse or segmental, hyperemic or pale optic disc edema. It is usually 
unilateral, and in contrast to diabetic papillopathy, damage to the optic nerve ganglions causes decreased visual acuity and/or visual field loss. Vision is usually not worse than $20 / 200$ and the typical visual field defect is altitudinal. Diabetes is a risk factor for NAION and the condition may present at a younger age in diabetic patients (Kline et al., 2010).

After an episode of NAION visual acuity may be stable but can also decline slowly over weeks to months until eventual stabilization. The initial finding upon examination is optic disc swelling, but this resolves over time and is replaced by optic disc atrophy within 4-8 weeks. There is no proven treatment for this condition.

\section{Diabetic retinopathy}

Damage to the retinal capillaries and other small vessels is the hallmark of diabetic eye disease and is known as diabetic retinopathy. This condition is the major cause of blindness and visual disability in patients with type 1 diabetes.

\subsection{Epidemiology}

Diabetic retinopathy is one of the most frequent causes of blindness in working aged adults (20-74 years) (Regillo et al., 2010; Cheung et al., 2010). In the USA an estimated 86\% of patients with type 1 diabetes have some degree of diabetic retinopathy. Data from the Wisconsin Epidemiologic Study of Diabetic Retinopathy (WESDR) showed that within 5 years of diagnosis of type 1 diabetes, $14 \%$ of patients developed retinopathy, with the incidence rising to $74 \%$ by 10 years (Klein et al., 2008; Varma, 2008). In people with retinopathy at the WESDR baseline examination, $64 \%$ had their retinopathy worsen, $17 \%$ progressed to proliferative diabetic retinopathy (PDR) and about $20 \%$ developed diabetic macular edema during 10 years of follow-up.

The WESDR data in type 1 diabetics showed that 25 years after diagnosis, $97 \%$ of patients developed retinopathy, 43\% progressed to PDR, 29\% developed diabetic macular edema and $3.6 \%$ of patients younger than 30 at diagnosis were legally blind (Klein et al., 2008). Fortunately, recent advances in glycemic control, ophthalmic treatment and patient education seem to be working. The WESDR results also showed a reduction in the yearly incidence and progression of diabetic retinopathy during the past 15 years (Varma 2008).

The course of diabetic retinal disease in children is fairly benign. Severe complications such as proliferative diabetic retinopathy are uncommon in children before puberty (Raab et al., 2010).

\subsection{Risk factors}

Several risk factors influence the development and progression of diabetic retinopathy. The following list contains most of the important risk factors known today.

1. Diabetes duration: The longer the duration of diabetes, the higher the risk of developing diabetic retinopathy and of having a severe manifestation of the disease. (Simon et al., 2010; Cheung et al., 2010).

2. Hyperglycemia: Good glycemic control has been shown to significantly prevent the development and progression of diabetic retinopathy. Every $1 \%$ decrease in hemoglobin $\mathrm{A}_{1 \mathrm{C}}$ leads to a $40 \%$ reduction in the risk of developing retinopathy, a $25 \%$ 
reduction in the risk of progression to vision threatening retinopathy and a $15 \%$ reduction in the risk of blindness (Cheung et al. 2010, DCCT group, 1995).

3. Hypertension: Good blood pressure control is important in reducing the risk of retinopathy. Every $10 \mathrm{mmHg}$ reduction in systolic blood pressure leads to a reduction of $35 \%$ in the risk of retinopathy progression and a reduction of $50 \%$ in the risk of visual loss (Cheung et al. 2010).

4. Hyperlipidemia: High cholesterol may also be a risk factor for diabetic retinopathy progression (Cheung et al., 2010).

5. Genetic factors: The Diabetes Control and Complications Trial (DCCT group, 1997) showed a heritable tendency for developing diabetic retinopathy, regardless of other risk factors.

6. Ethnicity: Diabetic retinopathy in America is more prevalent among African Americans, Hispanic and south Asian groups than in Caucasians with otherwise similar risk profiles (Cheung et al., 2010).

7. Pregnancy: Pregnancy is associated with worsening of diabetic retinopathy (DCCT group, 2000). All pregnant women need to be closely monitored throughout pregnancy. Pregnancy in type 1 diabetes is discussed in further detail in section 7.6.1.

\subsection{Pathophysiology}

The normal retina has a blood-retinal barrier (BRB) which consists of cells that are tightly joined together to prevent certain substances from entering the retinal tissue. An important part of the BRB is the non-fenestrated capillaries of the retinal circulation. In diabetic retinopathy, damage to retinal blood vessels leads to a breakdown of the BRB and the leakage of fluid, blood and protein into the retinal tissue.

Diabetic retinopathy is induced when hyperglycemia and other causal risk factors trigger a cascade of biochemical changes leading to microvascular damage in the retina. Hyperglycemia leads to rise of sorbitol concentrations via the action of aldose reductase. This process increases oxidative stress by reducing intracellular levels of reduced glutathione, an important antioxidant (Stirban et al., 2008). Intracellular hyperglycemia also increases synthesis of diacylglycerol an activating cofactor for protein kinase C (PKC). Activated PKC decreases the production of anti-artherosclerotic factors and increases production of pro-artherogenic factors, pro-adhesive and pro-inflammatory factors (Stirban et al., 2008). Hyperglycemia also leads to accumulation of advanced glycated end products which are pro-inflammatory and activate PKC (Stirban et al., 2008). Intracellular hyperglycaemia increases intracellular $\mathrm{N}$-acetylglucosamine levels. This byproduct reacts with serine and threonine residues in transcription factors, resulting in pathologic changes in gene expression (Stirban et al., 2008). The final consequence of these pathological processes is increased inflammation and increased oxidative stress which cause endothelial cell dysfunction in retinal blood vessels.

Endothelial cell dysfunction induces retinal arteriolar dilatation which increases capillary bed pressure. This results in microaneurysm formation, vessel leakage and rupture (Cheung et al., 2010). Vascular permeability is also increased from loss of pericytes and increased endothelial proliferation in retinal capillaries. The breakdown of the bloodretinal barrier allows fluid to accumulate in the deep retinal layers where it damages photoreceptors and other neural tissues. This is the mechanism by which macular edema reduces visual acuity. 
In some capillaries there is endothelial cell apoptosis. Vessels become acellular leading to vascular occlusion and non-perfusion of local retinal tissue (Stirban et al., 2008). The resultant retinal ischemia promotes the release of inflammatory growth factors, such as vascular endothelial growth factor (VEGF), growth hormone- insulin growth factor and erythropoietin (Cheung et al., 2010). These factors influence neovascularization, the proliferation of new capillaries, which is the hallmark of proliferative diabetic retinopathy.

\subsection{Classification and clinical features}

Diabetic retinopathy is classified into two stages: non-proliferative diabetic retinopathy (NPDR) and proliferative diabetic retinopathy (PDR). In NPDR the vascular changes occur within the retina and do not cross the retinal surface. The more advanced stage of PDR is marked by neovascularization wherein new blood vessels grow out from the retinal surface towards the vitreous cavity.

A major cause of vision loss in diabetic retinopathy is diabetic macular edema (DME). DME occurs when leaky capillary beds allow fluid to accumulate in the part of the retina responsible for central vision. This edema can occur in patients with any stage of underlying retinopathy from mild NPDR to severe PDR.

Visual impairment is usually related to the state of macular disease and the consequences of neovascularisation such as vitreous hemorrhage and retinal detachment. As such, the level of retinal disease does not always correlate with visual function and severe diabetic retinopathy can be present initially without significant visual loss.

\subsubsection{Non-proliferative diabetic retinopathy (NPDR)}

In NPDR the retinal microvascular changes occur within the retina and do not extend beyond the surface of the retina. The patient with NPDR is usually asymptomatic and visual acuity is preserved unless the macula is affected.

Clinical findings include microaneurysms (saccular enlargements of weakened capillaries), intra-retinal hemorrhages, hard exudates (lipid filled macrophages), cotton wool spots (nerve fiber layer infarcts)(figures 3-4), venous beading (focal venous dilatations and constrictions) and intra-retinal microvascular abnormalities (IRMA's, dilated pre-existing capillaries) (Regillo et al., 2010, Cheung et al., 2008).

Fluorescein angiography (FA) is an essential tool for evaluating the retinal circulation and retinopathy stage. Sodium fluorescein is injected into the systemic circulation, and an angiogram is obtained by photographing the fluorescence emitted after illumination of the retina. In NPDR, the FA shows microaneurysms as dye filled outpouchings. Hemorrhages appear as black dots as the blood obscures the fluorescence from the retina and choroid below (figure 5).

NPDR is classified as mild, moderate or severe, reflecting the risk of progression to PDR (Table 1) as determined by the Early Treatment in Diabetic Retinopathy Study (ETDRS) (ETDRS group, 1995). The diagnosis of severe NPDR is made when one of three findings is present: diffuse intra-retinal hemorrhages and microaneurysms in all 4 retinal quadrants, venous beading in 2 quadrants or one intra-retinal microvascular abnormalities anywhere. Fifteen persent of patients with severe NPDR will progress to high-risk PDR within 1 year. When any two features of severe NPDR are present, the patient is said to suffer from very severe NPDR and the one year risk of progression to high risk PDR increases to $45 \%$. 

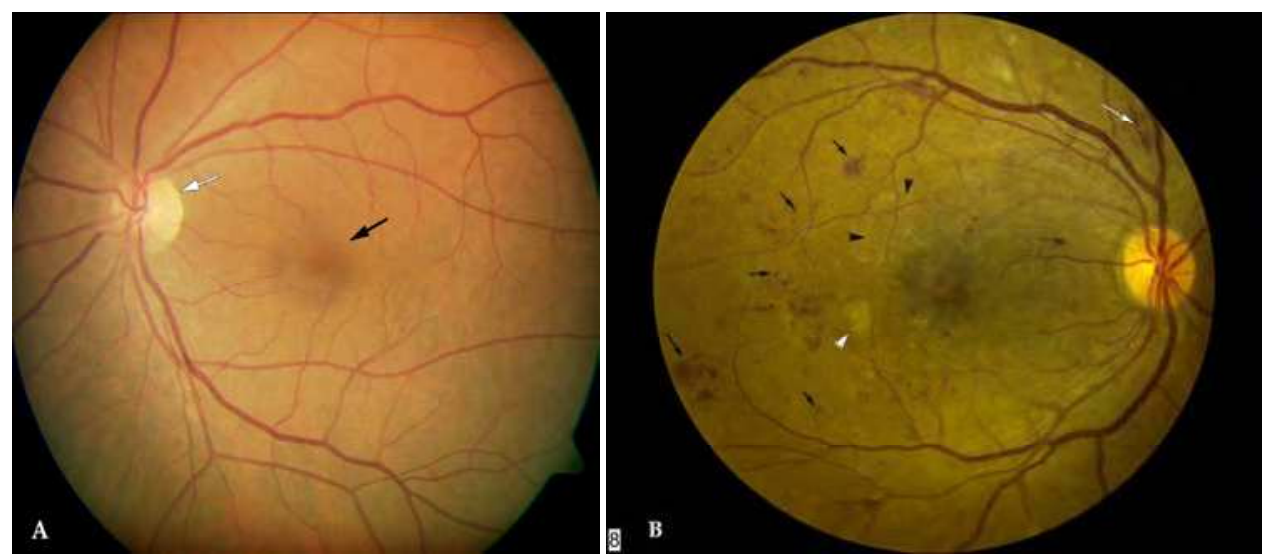

Fig. 3. A: Color photograph of normal fundus (left eye) normal optic disc (white arrow) and macula (black arrow). B: Color photograph (right eye) showing non-proliferative diabetic retinopathy and macular edema. Findings include; dot and blot hemorrhages (black arrows), flame shaped hemorrhages (white arrow), and cotton wool spot (white arrowhead) which represent nerve fiber layer infarcts. Hard exudates (black arrowheads) are lipid filled macrophages and in this photograph are radially distributed around the central macula.

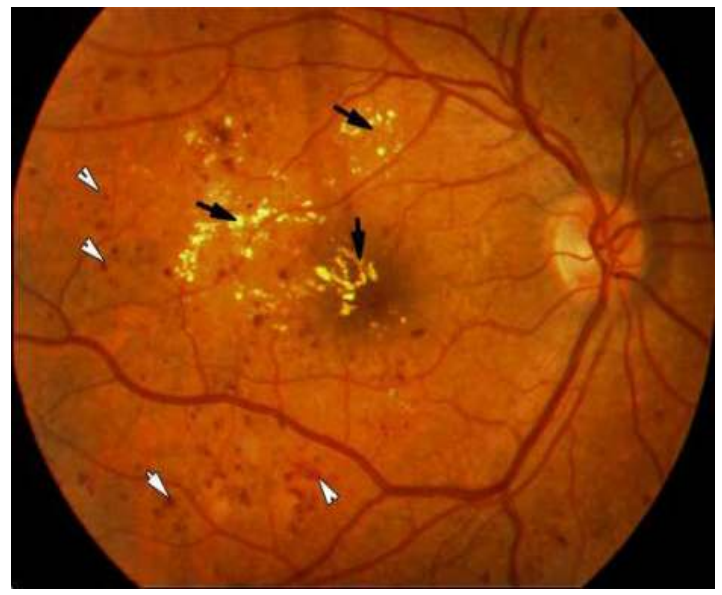

Fig. 4. Color photograph of fundus with moderate non-proliferative diabetic retinopathy with macular edema. Multiple dot and blot retinal hemorrhages are seen (white arrowheads) and hard exudates (black arrows). 


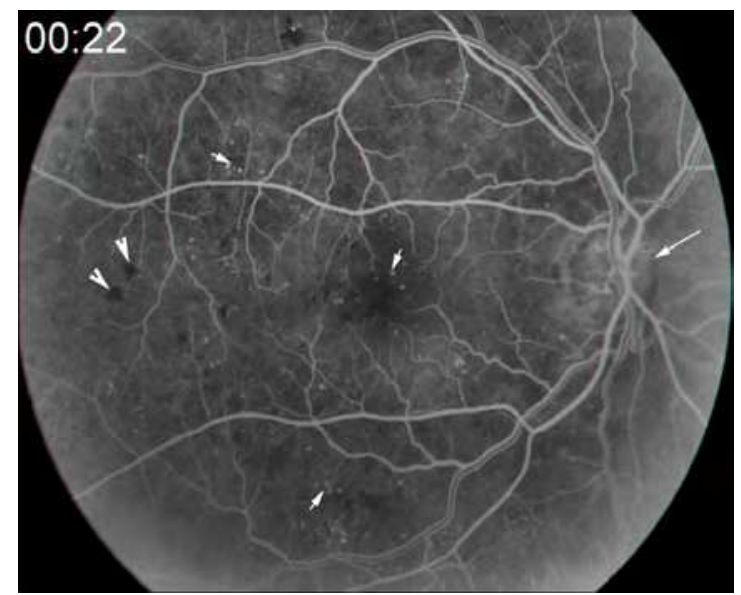

Fig. 5. Fluorescein angiography of non proliferative diabetic retinopathyof the right eye. Sodium fluorescein is injected into the systemic circulation, and an angiogram is obtained by photographing the fluorescence emitted after illumination of the retina. In NPDR the FA shows microaneurysms filled with dye (small white arrows). Hemorrhages appear as black dots because the transmission of fluorescence from below the hemorrhage is blocked (white arrowheads). The optic disc marked with long white arrow.

\begin{tabular}{|c|c|c|}
\hline Stage of NPDR & Clinical Features & Progression Risk \\
\hline Mild NPDR & Few microaneurysms & $\begin{array}{l}5 \% \text { progress to PDR within } \\
1 \text { year }\end{array}$ \\
\hline Moderate NPDR & $\begin{array}{l}\text { Microaneurysms and other } \\
\text { microvascular lesions }\end{array}$ & $\begin{array}{l}12-16 \% \text { progress to PDR } \\
\text { within } 1 \text { year }\end{array}$ \\
\hline $\begin{array}{l}\text { Severe NPDR } \\
\text { (Meets } 1 \text { of } 3 \text { criteria) }\end{array}$ & 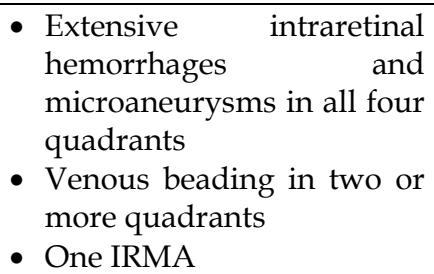 & $\begin{array}{l}52 \% \text { progress to PDR } \\
\text { within } 1 \text { year } \\
15 \% \text { progress to high risk } \\
\text { PDR within } 1 \text { year }\end{array}$ \\
\hline Very severe NPDR & $\begin{array}{l}\text { Any two of the features of } \\
\text { severe NPDR }\end{array}$ & $\begin{array}{l}45 \% \text { progress to high risk } \\
\text { PDR within } 1 \text { year }\end{array}$ \\
\hline
\end{tabular}

Table 1. Clinical classification of non-proliferative diabetic retinopathy

\subsubsection{Proliferative diabetic retinopathy (PDR)}

Diabetic retinopathy advances to the proliferative stage when new vessels (neovascularizations) are formed which grow up from the retina towards the vitreous cavity. The development of these pathological blood vessels is induced by pro-angiogenic factors released as a result of the severe retinal ischemia caused by the progression of diabetic retinal microvascular disease. Neovascularizations can be identified clinically as a jumble of disorganized, fine vessels emanating from the organized retinal vessel architecture (figure 6). Fluorescein angiography is also very effective at identifying 
neovascular lesions as the new vessels are porous and leak fluorescent dye into the vitreous cavity.

The new vessels in PDR evolve in three stages. Initially, the fine new vessels grow with minimal fibrous tissue. Then the new vessels increase in gauge and length with an increased fibrous component. Finally, the vessels regress and the residual fibrovascular tissue along the posterior surface of the vitreous body contracts.

Retinal neovascularizations (NV) are divided into two subtypes based on their relative risk of causing severe visual loss as demonstrated by the Diabetic Retinopathy Study (DRS). Vascular proliferations on or near the optic disc are termed NV-disc (NVD) and proliferations elsewhere are termed NV-elsewhere (NVE) (figures 6 - 8). The presence of NVD carries the higher risk of severe visual loss and requires more urgent treatment (DRS research group, 1979, 1981).

PDR is graded from early to high risk based on the risk of severe visual loss as determined by the extent of the neovascular proliferations. The DRS (DRS research group, 1979, 1981) defined high risk PDR as the presence of either: NVD with a vitreous hemorrhage, NVD larger than a quarter disc area without vitreous hemorrhage or NVE larger than half disc area with vitreous hemorrhage. Without treatment, patients with early PDR have $50 \%$ risk of developing high risk PDR in 1 year and those with high risk PDR have a $25 \%$ risk of severe visual loss within 2 years. Treatment of PDR involves extensive peripheral laser ablation of the retina and is discussed in section 7.5.2.3.

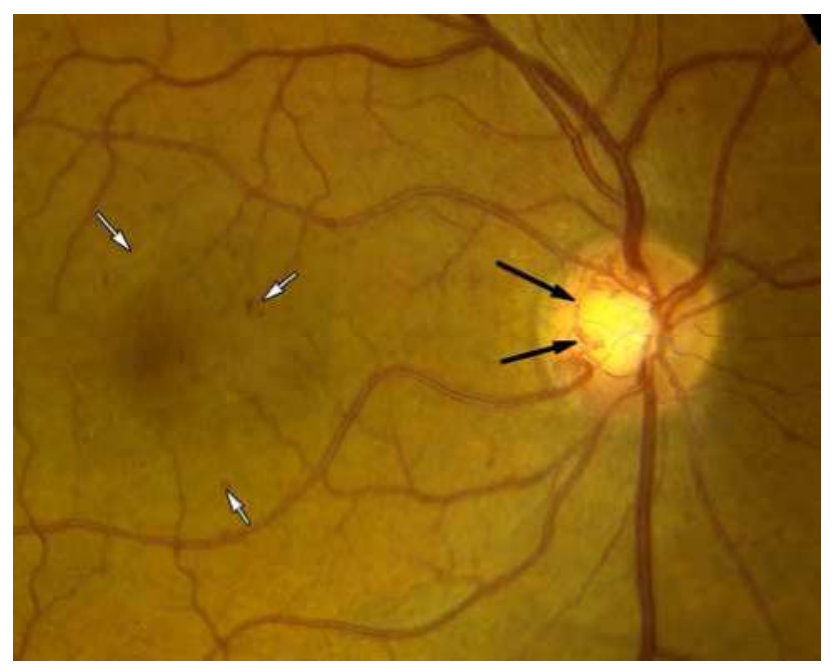

Fig. 6. Proliferative Diabetic Retinopathy with Neovascularization of the Optic Disc (NVD). Vascular proliferations on or near the optic disc are termed NV-disc (NVD). This Color photograph shows fine jumbled vessels (black arrows) typical of NVD. Multiple dot and blot retinal hemorrhages are seen (white arrows). 

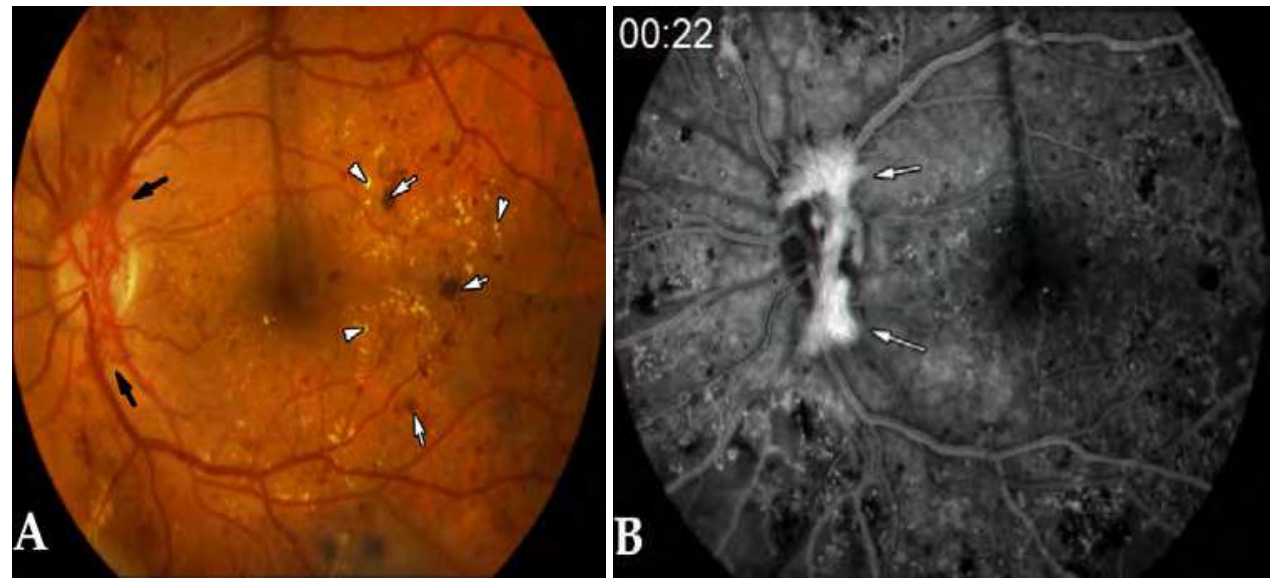

Fig. 7. High Risk Proliferative Diabetic Retinopathy with Large NVD. PDR is graded from early to high risk based on the risk of severe visual loss as determined by the extent of the neovascular proliferation. A: Color photograph showing a large neovascularization of the optic disc (black arrows) this NVD is larger than a quarter disc area therefore consistent with high risk PDR. Retinal hemorrhages (white arrows) and hard exudates (white arrowheads) are also seen. B: Fluorescein angiography in the same patient demonstrating hyper-fluorescence due to dye leakage from the disc neovascularization (white arrows).

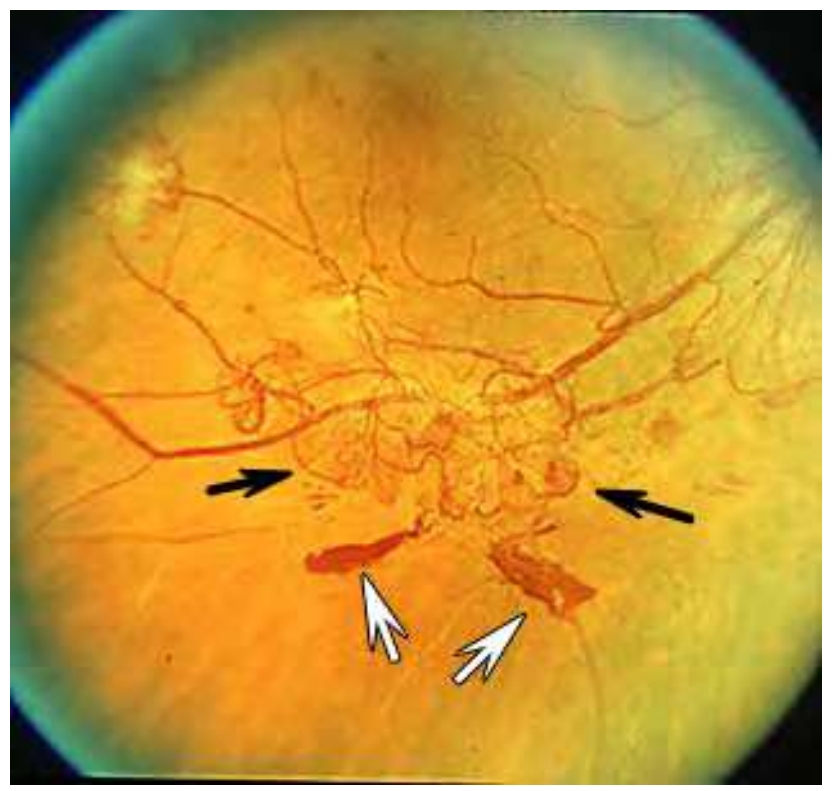

Fig. 8. High Risk Proliferative Diabetic Retinopathy with large NVE. This neovascular lesion located away from the optic disc is known as a Neovascularization-Elsewhere (NVE). This large NVE (black arrow) is associated with a small hemorrhage (white arrow). 
The most frequent complication of PDR is vitreous hemorrhage (figure 9) caused by rupture in the fragile neovascular vessels. The initial complaint is often of black dots partially obscuring vision and can evolve to severe visual loss over a period of hours to days as the eye fills with blood.

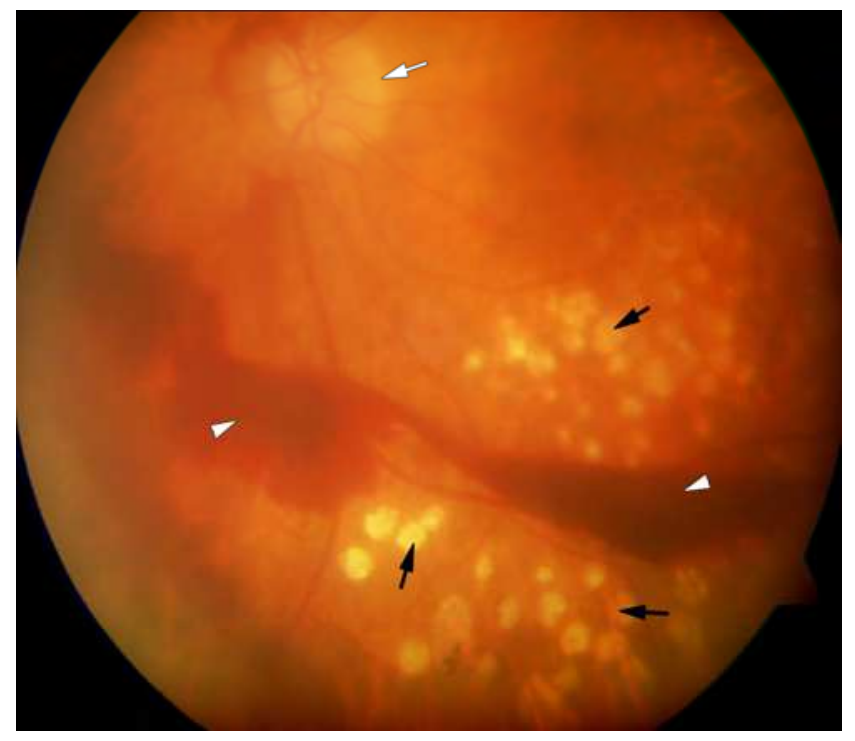

Fig. 9. Vitreous Hemorrhage. Vitreous hemorrhage is the most frequent complication of PDR. It is caused by rupture of neovascular vessels. This color figure shows partial vitreous hemorrhage causing general haze. Dense blood in the vitreous cavity is seen (white arrowheads). This hemorrhage occurred in eye after the initiation of pan-retinal photocoagulation as a treatment for PDR. Multiple white-yellow laser burns are seen (black arrows). This treatment is discussed in section 7.5.2.3. The optic disc is also seen (white arrow). 
Another cause of severe vision loss in PDR is traction retinal detachment. This detachment occurs when the neovascular tissue connecting the retinal surface to the vitreous contracts causing a separation between the surface and deep retinal layers (figure 10). If this occurs in the center of the macula severe vision loss can result.

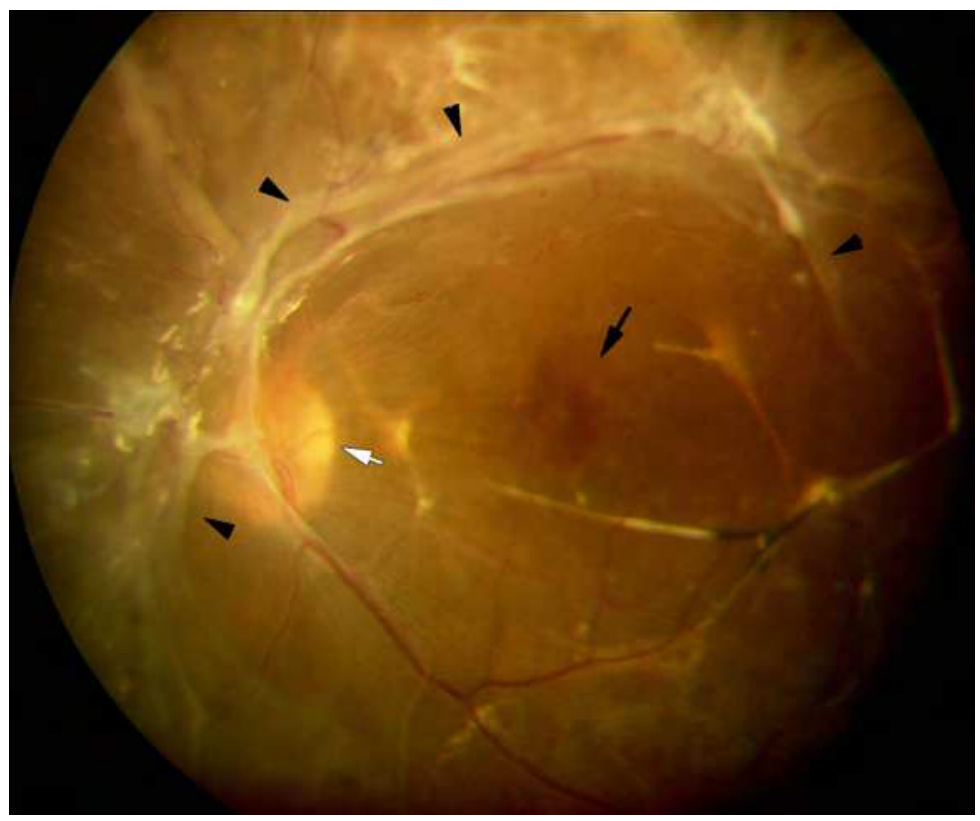

Fig. 10. Traction Retinal Detachment. This detachment is one of the serious complications in PDR and may cause severe visual loss. It occurs when the neovascular tissue connecting the retinal surface to the vitreous contracts causing a separation between the surface and deep retinal layers. This color fundus photograph shows elevated and detached retina (black arrowheads) involving the optic disc area (white arrow). The retina at the center of the macula (black arrow) is not detached.

A third serious complication of PDR occurs when proliferative and pro-angiogenic factors released from the ischemic retina induce the propagation of new vessels on the iris (figure 1). These vessels can block the normal outflow of fluid from the eye causing often severely increased ocular pressure. This complication is known as neovascular glaucoma and is discussed further previously in section 5 .

Visual acuity in the absence of macular disease is often good in PDR until a complication occurs, most commonly vitreous hemorrhage. This sudden transition from good vision to near blindness can be traumatic for patients who were unaware of the severity of their diabetic eye disease.

\subsubsection{Diabetic macular edema}

Diabetic macular edema (DME) is responsible for most of the moderate visual loss in retinopathy patients. The vision loss is often mild at first, but without effective treatment it can progress and patients can lose the ability to perform activities of daily 
living such as reading and driving. Diabetic macular edema is assessed separately from the stage of retinopathy (NPDR/PDR) and it can manifest along a different and independent course.

The edema evolves when damage to the macular capillary bed causes a breakdown of the blood-retina barrier. This results in increased retinal vascular permeability and to the accumulation of fluid in the macula. Macular edema may be 'focal' and emanate from a small cluster of leaky vessels, or 'diffuse' and involve the entire macula without a clear point of origin. Clinical examination can reveal rings of hard exudates (lipid filled macrophages) which delineate the area of focal leakage (figures $3 \& 4$ ). These subtypes are often differentiated by angiography which demonstrates areas of focal leakage from specific capillary lesions and microaneurysms in focal edema. In diffuse macular edema, angiography reveals widespread leakage with no definitive point of origin from extensive breakdown of the blood-retinal barrier (Regillo et al., 2010).

Treatment decisions are based on the clinical examination in DME. Intervention is recommended only when the retinal edema involves or threatens the center of the macula. In all other cases, close follow-up alone is indicated (ETDRS group, 1995).

Optical Coherence Tomography (OCT) is a useful ancillary imaging technique in DME. Recent technological advances in OCT technology have provided ophthalmologists with high-resolution images of the retina in cross-sectional slices. Aside from demonstrating areas of retinal thickening and intra-retinal fluid (figure 11), OCT obtains quantitative measurements of central retinal thickness that are important for close monitoring and follow-up of macular edema. Serial OCT examinations are often used as a non-invasive and accurate method analyzing treatment response in DME patients (Cheung et al., 2008).
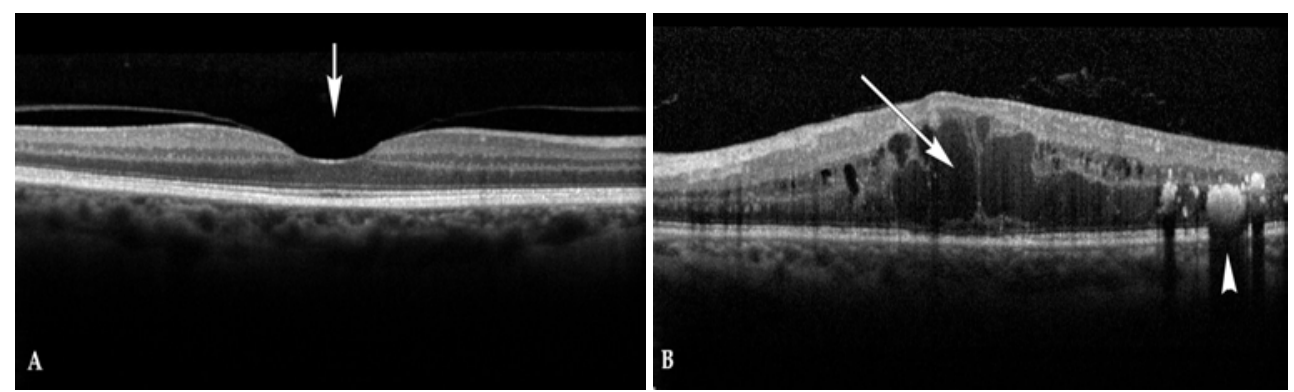

Fig. 11. Optical Coherence Tomography (OCT) of the Macula. A: OCT scan demonstrating the normal anatomic indentation in the central macula in a healthy eye (white arrow). B: Diabetic macular edema: There is loss of central macular indentation due to retinal cysts (white arrow). Hard exudates are also seen (white arrowhead).

\subsubsection{Diabetic macular ischemia}

Macular ischemia is a devastating complication of diabetic retinopathy. It is caused by extensive loss of retinal capillary perfusion in the macula. Clinical exam often reveals microaneurysms clustering at the margins of the non-perfused retina. Angiography can demonstrate the presence and extent of the area with capillary non-perfusion. This entity is generally associated with significantly decreased vision (Regillo et al., 2010). 


\subsection{Treatment and prevention of diabetic retinopathy}

The main goal of treatment of diabetic retinopathy is preventing complications which can lead to vision loss. Treatment should include both ocular therapy and systemic medical intervention.

\subsubsection{Medical treatment}

Hyperglycemia, hypertension and hyperlipidemia are known risk factors for the development and progression of diabetic retinopathy. Treating and controlling these factors is crucial to preventing and limiting disease progression.

The Diabetes Control and Complications Trial (DCCT group, 1995) showed that intensive glycemic control reduced both the risk of developing retinopathy and the rate of progression of existing retinopathy. Intensive glycemic control reduced the risk for progression to severe NPDR and PDR, the incidence of diabetic macular edema and the need for laser treatments. Every percent reduction in hemoglobin $\mathrm{A}_{1 \mathrm{C}}$ lowers the risk of retinopathy development by $30-40 \%$.

Several other systemic therapies have been investigated and found to reduce the risk of retinopathy progression including Angiotensin Converting Enzyme Inhibitors, Protein Kinase C Inhibitors and inhibitors of Advanced Glycosylation End-products formation (Cheung et al., 2008).

\subsubsection{Ocular treatment}

Ocular therapy in diabetic retinopathy includes panretinal or focal laser photocoagulation, intravitreal injections of either steroids or inhibitors of Vascular Endothelial Growth Factor (VEGF), surgery or a combination of the aforementioned treatments. The suitable treatment regimen must be tailored individually for each patient and is based on clinical status of the patient (ocular and systemic), previous treatments and data from several reports and ongoing studies.

\subsubsection{NPDR}

Visual acuity is not usually affected in NPDR unless there is damage to the macula in the form of macular edema or ischemia. Ocular treatment at this stage is definitively indicated only if there is evidence of macular disease. In patients with very severe NPDR who are at high risk for progression to PDR, laser treatment can be considered if the patient is not considered a suitable candidate for close follow-up. In such cases the recommended treatment is Pan- Retinal laser Photocoagulation (PRP) which will be discussed in section 7.5.2.3 (ETDRS group, 1995).

\subsubsection{Diabetic macular edema (DME)}

Treatment options for DME include focal laser photocoagulation, intravitreal injections of either steroids or anti-VEGF compounds and surgery.

\subsection{Focal laser}

The mainstay of DME treatment is focal laser photocoagulation. Focal laser treatment for DME involves the application of discrete laser burns to areas of leakage in the macula. The treatment is not painful and can be repeated up to every 4 months if edema persists. Treatment criteria are based on the ETDRS recommendations (ETDRS group, 1995) which showed that eyes with macular edema involving or threatening the central macula, defined 
as clinically significant macular edema (CSME), benefited from focal laser treatment. Focal laser treatment reduced the risk of moderate visual loss (loss of three lines of vision) by $50 \%$ over two years, increased the chance of improved vision and reduced central macular thickness compared to no treatment.

In eyes with macular edema that does not meet the criteria for CSME, laser treatment is not indicated. Close follow-up is recommended to determine the progression of the macular edema. Unfortunately, when the macular edema is associated with macular ischemia from a loss of macular capillary perfusion, the ETDRS showed a lesser beneficial effect for focal laser (ETDRS Group, 1995).

Side effects of focal laser photocoagulation include: paracentral visual field loss, transiently increased macular edema with decreased visual acuity and choroidal neovascularization (Regillo et al, 2010).

\subsection{Steroid injections}

Inflammatory factors play an important role in the development of diabetic retinopathy and macular edema (see section 7.3). For this reason it has long been thought that ocular steroid injections may be beneficial in DME treatment. Several trials have shown modestly improved visual acuity and central macular thickness after injection of intravitreal Triamcinolone (Grover at al., 2008; Yilmaz et al., 2009). A few recent trials on long acting steroid implants, such as Fluocinolone Acetate or Dexamethasone, have also reported short term visual acuity improvements (Grover et al., 2009).

The Diabetic Retinopathy Clinical Research Network (DRCR network, 2008) compared intravitreal injection of Triamcinolone to focal laser treatment in eyes with DME. There was no difference in visual acuity between the two groups after 1 year, and at 2 years eyes treated with laser had better vision. However, complications of intravitreal steroids, including elevated ocular pressure and increased cataract progression limit the usefulness of these drugs in DME. Intravitreal sterioid injections may be considered in patients who have previously undergone cataract surgery and in cases where the macular edema is refractory to focal laser. In these cases the injections may be given either alone or as an adjunct to laser treatment (Gillies et al., 2006; Maia et al., 2009).

\subsection{Anti-vascular endothelial growth factor (VEGF) compounds}

Vascular Endothelial Growth Factor (VEGF) is a major cause of the increased retinal vascular permeability which causes macular edema (Stirban et al., 2008). Several VEGF inhibitors have been investigated as treatments for DME with a beneficial effect on visual acuity and central macular thickness.

Injection of intravitreal Pegaptanib, a pegylated aptamer that inhibits one isoform of VEGF, was found to be better than sham injections in improving in visual acuity and decreasing the need for focal laser treatment, in the Macugen Diabetic Retinopathy Study group (Cunningham et al., 2005).

The injection of monoclonal antibodies that block all isoforms of VEGF has also been investigated as a treatment for DME. Several studies have shown a beneficial effect on visual acuity in eyes treated with Bevacizumab (trade name Avastin), a recombinant full length humanized antibody to VEGF (Nicholson \& Shachat, 2010). Based on data from multiple studies (Nicholson \& Shachat, 2010) repeated doses of Bevacizumab increase its average positive effect. The optimal timing for repeat dosing is unclear, but is probably between 3 to 12 weeks, with maximal effect with a 3 to 6 weeks interval between treatments. 
The Bevacizumab Or Laser Treatment study (Michaelidis et al., BOLT study, 2010) compared 6-weekly bevacizumab injections to focal laser treatment in DME. One year postrandomization, eyes treated with bevacizumab had significantly better vision by over one line of acuity and less macular edema compared to eyes treated with focal laser. Bevacizumab treated eyes also had fivefold greater odds gaining at least 2 lines of vision.

Another promising drug that targets VEGF is Ranibizumab (trade name Lucentis). This a recombinant, humanized antibody fragment binds and inhibits all isoforms of VEGF. A recent study compared four treatment options; monthly injections of Ranibizumab combined with focal laser, monthly Ranibizumab alone with the option for rescue focal laser treatment, focal laser treatment alone and focal laser combined with intravitreal injections of Triamcinolone (DRCR network 2010a). After 1 year, eyes that received intravitreal injections of Ranibizumab, either combined with laser or with the option for rescue laser had better visual acuity compared with the other treatment groups. On average, eyes receiving Ranibizumab gained 1 line in visual acuity after 1 year. Half of Ranibizumab treated patients gained more than 2 lines in visual acuity, and $30 \%$ gained 3 lines or more. Two years results showed a similar positive treatment effect in DME with Ranibizumab injections.

The injection of anti-VEGF agents to the vitreous is both effective and safe. Adverse ocular effects include: cataract formation, retinal detachment, vitreous hemorrhage and infection. Potential systemic adverse effects include: hypertension, stroke, and myocardial infarction but these are very uncommon (Cheung et al., 2010; Nicholson \& Shachat, 2010).

\subsection{Surgical intervention}

DME can also be treated surgically by performing a vitrectomy. This option is used sparingly because of the utility of both laser treatments and intravitreal injections in controlling the disease. Surgery is indicated in cases refractory to other treatments or when there is mechanical traction on the macula from vitreo-retinal adhesions. In such cases edema resolution can often not be obtained without resorting to intraocular surgery where the traction can be definitively released (Kaiser et al., 2001; DRCR network, 2010b).

\subsubsection{Proliferative diabetic retinopathy (PDR) treatment}

\subsection{Panretinal photocoagulation (PRP)}

The goal of treatment in PDR is to prevent complications and lower the risk of severe vision loss. The mainstay of treatment for PDR is laser ablation of the peripheral retina. In this treatment, known as panretinal photocoagulation (PRP), laser burns are placed over the entire retina, sparing only the central macula (figure 12). PRP promotes the regression and arrest of progression of retinal neovascularizations by destroying ischemic retinal tissue and reducing ischemia driven VEGF production (Cheung et al., 2010; Regillo et al., 2010).

The Diabetic Retinopathy Study (DRS) evaluated efficacy of PRP treatment in eyes with advanced NPDR or PDR (DRS Group, 1981). The DRS study recommended prompt treatment in eyes with high risk PDR (defined in section 7.4.2), because these eyes had the highest risk for severe visual loss. PRP treatment in these patients reduced the risk of severe visual loss by $50 \%$ over 5 years. The ETDRS study found that PRP treatment in eyes with early PDR reduced the risk of progression to high risk PDR by $50 \%$, and significantly reduced the risk of severe visual loss (ETDRS Group, 1995). Based on these results, PRP treatment should be considered in eyes with any stage PDR especially if there is poor metabolic control, a non compliant patient or difficulty in maintaining close follow-up. 


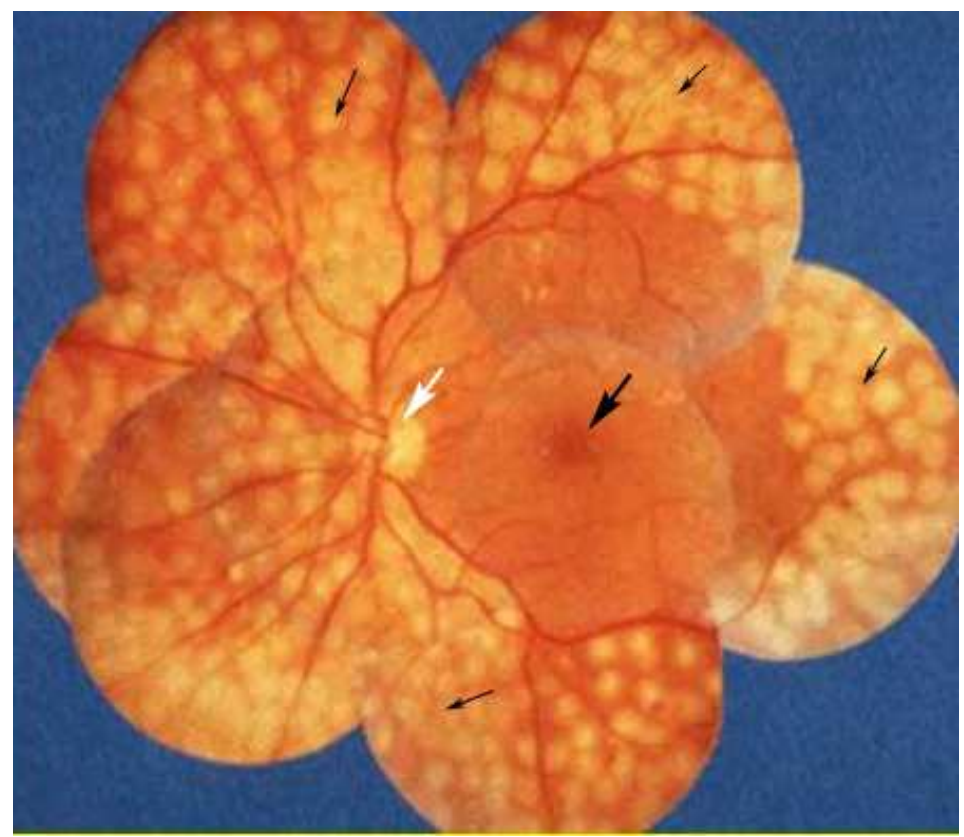

Fig. 12. Pan-Retinal Photocoagulation. The mainstay of treatment for PDR is laser ablation of the peripheral retina. In this treatment, known as panretinal photocoagulation (PRP), laser burns are placed over the entire retina (small black arrows), sparing only the central macula (large black arrow) and the optic disc (white arrow).

Full PRP treatment as recommended by the DRS and the ETDRS includes as many as 4000 laser burns. PRP can be painful and is often performed over several sessions. After the initial treatment course, additional therapy can be applied if there is persistent neovascularisation. After treatment, proliferative retinal tissue may regress and contract causing a vitreous hemorrhage or a traction retinal detachment from contracture of fibrovascular tissue. Side effects of PRP treatment also include; decreased in night vision, decreased color vision and loss of peripheral vision. These side effects can be reduced by spreading out the treatment sessions and by using less energy at each session (Regillo et al. 2010).

When PDR presents with macular edema, PRP treatment may initially increase the amount of the edema (ETDRS Group, 1991). In such case it is recommended to treat the macular edema with either focal laser or an intravitreal injection before initiating PRP (Silva et al., 2009, Mirshani et al., 2008).

\subsection{Vitreous hemorrhage}

In patients with new onset vitreous hemorrhages, laser PRP treatment is recommended if visualization of the retina is adequate. A severe, dense, non-clearing vitreous hemorrhage is an indication for vitrectomy surgery. The Diabetic Retinopathy Vitrectomy Study (DRVS Group, 1985) recommended surgery within 1 to 6 months of vitreous hemorrhage onset in type 1 diabetes patients with a non-clearing vitreous hemorrhage. Early vitrectomy improved visual acuity outcomes compared with waiting up to a year for spontaneous resolution before resorting to surgery. 
Recent advances in vitreoretinal surgery, including smaller gauge instruments and the ability to perform laser ablation during surgery, have changed treatment recommendations. If a patient with a vitreous hemorrhage has not previously undergone PRP, vitrectomy is recommended when a dense vitreous hemorrhage persists beyond one to three months. Patients with vitreous hemorrhage that have preexisting complete PRP may undergo a longer observation period (Regillo et al., 2010).

Several studies have evaluated the efficacy of intravitreal anti-VEGF injections in patients with PDR (Nicholson \& Shachat, 2010). Intravitreal Bevacizumab as adjunctive therapy with PRP was found to decrease leakage area from neovascularizations, improve visual acuity outcomes and reduce macular edema compared with PRP alone. In eyes with PDR and a dense vitreous hemorrhage preventing full PRP treatment, a Bevacizumab injection has been shown to aid significantly in clearing the hemorrhage (Moradian et al., 2008).

Bevacizumab has also been shown to enhance retinal surgery in patients with PDR. A single Bevacizumab injection given 1-2 weeks before vitrectomy for vitreous hemorrhage, results in decreased bleeding during surgery, decreased operating time and less post operative vitreous hemorrhage as compared to vitrectomy alone (Nicholson \& Shachat, 2010; Ahmadieh et al.,2009).

\subsection{Traction retinal detachment}

Traction retinal detachment from the contraction of the neovascular tissue connecting the retinal surface to the vitreous is another serious complication of PDR. However, traction detachments which do not involve the macula can remain stable for years. Vitrectomy surgery is indicated only when the traction retinal detachment involves or threatens the central macula or if a retinal tear develops (Regillo et al. 2010).

\subsection{Neovascular glaucoma}

A third serious complication of PDR occurs when high levels of VEGF in the retina induce the development of new vessels on the iris. These vessels threaten to block the outflow of aqueous fluid from the eye and raise ocular pressure. The treatment of patients with neovascularisation of the iris involves both the minimization of retinal ischemia and the aggressive reduction of intraocular pressure if elevated. Retinal ischemia is treated with aggressive and extensive ablation of peripheral retinal tissue with PRP regardless of the stage of PDR. Injection of intravitreal anti-VEGF agents as adjunctive therapy to PRP can induce a rapid reduction or resolution of neovascularisation of the iris (Ahmadieh et al., 2009; Wasik et al., 2009). However, these injections should be seen as an adjunct to full PRP which remains the definitive treatment and not as a viable replacement.

Elevated ocular pressure in neovascular glaucoma is treated initially with topical medications. Often multiple drops are required to reduce pressure to below the target level of approximately 20 millimeters of mercury. In advanced cases, topical treatment alone may not be sufficient and systemic treatment with carbonic anhydrase inhibitors such as Acetazolamide may be considered. Common side effects of Acetazolamide include numbness and tingling in the fingers and toes, and taste alterations. Acetazolamide also increases the risk of dehydration and metabolic acidosis. Serial electrolyte and kidney function tests are recommended in all patients receiving this medication. 
In refractory cases Cyclodestructive procedures are required if medical therapy fails to provide symptomatic relief. With cyclocryotherapy, the IOP-lowering effect is achieved by destroying secretory ciliary epithelium and/or reducing blood flow to the ciliary body. It is indicated as a last resort only if relief of pain is the main goal.

\subsection{Special considerations}

\subsubsection{Diabetic retinopathy in pregnancy}

In women with preexisting diabetes, pregnancy is considered an independent risk factor for the development and progression of diabetic retinopathy (Shultz et al., 2005). Gestational diabetes, in absence of preexisting diabetes does not show a similar association with diabetic retinopathy. Most of the progression of diabetic retinopathy in pregnancy occurs by the end of the second trimester. Although regression of retinopathy usually occurs postpartum, there is still an increased risk for progression during the first year postpartum (Shultz et al., 2005). Risk factors for the development and progression of diabetic retinopathy in pregnancy include longer duration of diabetes before conception, rapid normalization of hemoglobin $\mathrm{A}_{1 \mathrm{C}}$ at the beginning of pregnancy, poor glycemic control during pregnancy, diabetic nephropathy, high blood pressure and preeclampsia (Shultz et al., 2005; Vestgaard et al., 2010).

Severity of diabetic retinopathy before or at beginning of pregnancy is also a strong predictor of progression of retinopathy during and after pregnancy. The Diabetes in Early Pregnancy Study (Chew et al., 1995) showed that $10.3 \%$ of women without diabetic retinopathy and $18.8 \%$ with mild NPDR experienced retinopathy progression during pregnancy, and $6.3 \%$ of women with mild NPDR progressed to PDR. In women with moderate NPDR, $54.8 \%$ suffered retinopathy progression and $29 \%$ developed PDR. Overall, progression to sight threatening diabetic retinopathy, including macular edema and PDR, occurs in $6 \%$ of pregnant diabetic women (Vestgaard et al., 2010).

Progression of retinopathy during pregnancy is probably related to the hypervolemic and hyper-coagulable states in pregnancy, as well as elevated pro-inflammatory and angiogenic factor levels. This results in capillary occlusion and leakage aggravating diabetic retinopathy mechanisms (Shultz et al., 2005; Kastelan et al., 2010). Ideally, good glycemic control and full treatment of pre-existing diabetic retinopathy complications should be attained before conception.

All diabetic women who plan pregnancy should be referred by their treating physician to an ophthalmologist. The recommended follow-up of pregnant women with type 1 diabetes includes an ophthalmologic exam at the beginning of pregnancy and during the first trimester. Subsequent follow-up depends on the stage of diabetic retinopathy found on the initial examinations. In women with no retinopathy or very mild NPDR, an ophthalmologic exam is indicated when there are visual complaints. In moderate NPDR an exam should be done at least once during the second trimester and every 4-6 weeks during the third trimester. In severe NPDR and PDR, close follow-up is needed, and an exam should be done every 4-6 weeks, from the beginning of the second trimester.

Treatment of diabetic retinopathy during pregnancy includes maximal control of both glucose levels and blood pressure (Vestgaard et al., 2010). Ocular therapy such as PRP should definitely be performed for PDR and be strongly considered in cases of severe NPDR. Disease progression can be very fast in pregnancy and waiting for PDR to clearly 
develop may result in severe complications that necessitate invasive surgery. Ocular therapy for PDR and macular edema during pregnancy can include PRP, focal laser and intravitreal injections of Triamcinolone. Although there is not much data on the safety of intravitreal injections of anti-VEGF agents during pregnancy, the literature includes some reports on the safe and effective use of Bevacizumab (Tarantola et al., 2010).

\subsubsection{Cataract surgery in patients with diabetic retinopathy}

Cataract is a major factor which compromises vision in diabetic patients. While diabetics may benefit from cataract extraction, a controversy exists in the ophthalmic community as to whether cataract surgery potentiates diabetic retinopathy progression. Several studies have reported worsening of diabetic retinopathy and macular edema after surgery (Pollack et al., 1991; Hauser et al., 2004; Jaffe et al., 1992, Hayashi et al., 2009). Progression was seen during the first year after surgery and was highest in the first 3 months postoperatively. A review of several other studies, especially in the cataract surgery era using the smaller incision phacoemulsification technique, showed no significant progression of diabetic retinopathy and macular edema after surgery (Rashid \& Young, 2010; Shah \& Chen, 2010). Overall, diabetics with cataracts benefit from surgery, and improved visual acuity is reported in $92-94 \%$ of patients (Rashid \& Young, 2010). The combined evidence suggests that in patients with low risk or absent diabetic retinopathy and no clinically significant macular edema at the time of surgery, there is little increased risk of retinopathy progression. However, in patients with severe NPDR, PDR or significant macular edema, cataract surgery carries an increased risk for retinopathy progression and a worse visual acuity outcome.

Recent studies have shown a potential benefit using intravitreal injection of Bevacizumab at the end of cataract surgery (Cheema et al., 2009; Chen et al., 2009; Nicholson \& Shachat, 2010) especially in cases with poorly controlled or refractory macular edema and diabetic retinopathy before surgery. Patients who received intravitreal Bevacizumab enjoyed better outcomes in terms of visual acuity, macular thickness and retinopathy progression.

A thorough evaluation of patients with diabetes is warranted before cataract surgery. Patients who have severe NPDR or PDR should be considered for PRP treatment prior to cataract removal (Chew et al., 1999). Patients with clinically significant macular edema should undergo treatment, such as focal laser or intravitreal injection of anti- VEGF agents pre-operatively. Ideally, surgery should be delayed until stabilization of retinopathy and macular edema is achieved. In refractory cases, adjunctive therapy with an anti-VEGF agent at the end of cataract surgery should be considered. Close post-operative follow-up with an ophthalmologist is highly recommended in all patients with preexisting diabetic retinopathy.

\section{Schedule for ophthalmologic examinations}

Regular ocular examination can detect early ocular disease such as cataracts and glaucoma as well as retinopathy. Diabetic retinopathy in type 1 diabetes is rare during the first 5 years after diagnosis, so the baseline ophthalmologic examination could be extended to 5 years after diagnosis if blood glucose has been well controlled. In children with pre-pubertal diabetes, the baseline examination should be done at puberty (Raab et al. 2010). 
The timing and frequency of follow-up ocular examinations depends on individual patient's status. In high risk patients with long term diabetes and poor systemic risk factor control annual examinations should be performed even in the absence of retinopathy. In patients with known retinopathy, the examination schedule is based on the degree of retinopathy, and on the patient's compliance and adherence to regular follow-up. In more advances stages such as PDR and when macular edema is present, more frequent and careful followup is suggested. (Regillo et al., 2010). Table 2 shows the recommended schedule for followup.

\begin{tabular}{|l|l|}
\hline Retinopathy Stage & Follow-up Schedule \\
\hline Normal or rare microaneurysms & Annually \\
\hline Mild NPDR & Every 9 months \\
\hline Moderate NPDR & Every 6 months \\
\hline Severe NPDR & Every 2-4 months \\
\hline Clinically significant macular edema & Every 2-4 months \\
\hline PDR & Every 2-3 months (careful follow-up) \\
\hline
\end{tabular}

Table 2. Suggested time table for follow-up in diabetic retinopathy (modified from the Preferred Practice Patterns committee, retina panel, diabetic retinopathy, American Academy of Ophthalmology, 2003, as cited in Regillo et al., 2010).

\section{Summary}

Management of type 1 diabetes involves close cooperation between the treating primary physician and the many specialists who help manage the complications of this disease. Recent advances, including intraocular anti-VEGF injections, have added important new tools which minimize vision loss in diabetic eye disease. Proactive, interdisciplinary coordination of treatment and timely referrals can aid in the minimization of visually threatening complications, significantly enhancing patient quality of life.

\section{References}

Ahmadieh H.; Shoeibi N.; Entezari M.; Monshizadeh R. (2009). Intravitreal Bevacizumab for prevention of early postvitrectomy hemorrhage in diabetic patients: a randomized clinical trial. Ophthalmology, Vol. 116, No.10, (October 2010), pp. 1943-1948, ISSN 0161-6420

Bobrow JC.; Blecher MH.; Glasser D. et al. (Eds.) (2010). Section 11: Lens and cataract. Basic and Clinical Science Course, 2010-2011, American Academy of Ophthalmology. Americam Academy of Ophthalmology, ISBN 9781615251391 
Bonini-Filho M.; Costa RA.; Calluci D. et al. (2009). Intravitreal Bevacizumab for diabetic macular edema associated with severe capillary loss: one year results of a pilot study. American Journal of Ophthalmology, Vol.147, No.6, (June 2009), pp. 1022-1020, ISSN 0002-9394

Cheema RA.; Al- Mubarak MM.; Amin YM. et al. (2009). Role of combined cataract surgery and intravitreal Bevacizumab injection in preventing progression of diabetic retinopathy; prospective randomized study. Journal of Catarct and Refractive Surgery, Vol.35, No.1, (January 2009), pp. 18-25, ISSN 0886-3350

Chen CH.; Liu YC.; Wu PC. (2009). The combination of intravitreal Bevacizumab and phacoemulsification surgery in patients with cataract and coexisting diabetic macular edema. Journal of Ocular Pharmacology Therapeutics, Vol.25, No.1, (February 2009), pp. 83-89, ISSN 1080-7683

Cheung N.; Mitchell P.; Wong TY. (2010). Diabetic Retinopathy. The Lancet, Vol.376, No.9735, (July 2010), pp. 124-136, ISSN 0140-6736

Chew EY.; Benson WE.; Remaley NA. et al. (1999). Results after lens extraction in patients with diabetic retinopathy; early treatment diabetic retinopathy study report number 25. Archives of Ophthalmology, Vol.117, No.12, (December 1999), pp. 16001606, ISSN 0003-9950

Chew EY.; Mills JL.; Metzger BE. et al. (1995). Metabolic control and progression of retinopathy. The Diabetic in Early Pregnancy Study. National Institute of Child Health and Human Development. Diabetes in Early Pregnancy Study. Diabetes Care, Vol.18, No.5, (May 1995), pp. 631-637, ISSN 0149-5992

Cunningham ET.; Adamis AP.; Altaweel M. et al. (2005). Macugen Diabetic Retinopathy Study Group. A phase II randomized double-masked trial of Pegaptanib, an anti-vascular endothelial growth factor aptamer, for diabetic macular edema. Ophthalmology, Vol.12, No.10, (October 2005), pp. 1747-1757, ISSN 01616420

DCCT 1995: Progression of retinopathy with intensive versus conventional treatment in the Diabetes Control and Complications Trial. Diabetes Control and Complications Trial Research Group. Ophthalmology, Vol.102, No.4, (April 1995), pp. 647-661, ISSN 0161-6420

DCCT 1997: Clustering of long term complications in families with diabetes in the diabetes control and complications trial. The Diabetes Control and Complications Trial Research Group. Diabetes, Vol.46, No.11, (November 1997), pp.1829-1839, ISSN 0012-1797

DCCT 2000: Effect of pregnancy on microvascular complications in the diabetes control and complications trial. The Diabetes Control and Comlications Trail Research Group. Diabetes Care, Vol.23, No.8, (August 2000), pp. 1084-1091, ISSN 0149-5992

DRCR network 2008: The Diabetic Retinopathy Clinical Research Network: A randomized trial comparing intravitreal Triamcinolone acetonide and focal/grid photocoagulation for diabetic macular edema. Diabetic Retinopathy Clinical Research Network. Ophthalmology, Vol.115, No.9, (Spetember 2008), pp. 14471449,e1-10, ISSN 0161-6420 
DRCR network 2010a: The Diabetic Retinopathy Clinical Research Network. Randomized trial evaluating Ranibizumab plus prompt or deferred laser or Triamcinolone plus prompt laser for diabetic macular edema. Ophthalmology, Vol.117, No.6, (June 2010), pp. 1067-1077, ISSN 0161-6420

DRCR network 2010b: Diabetic Retinopathy Clinical Research Network writing committee on behalf of the DRCR.net. Vitrectomy outcomes in eyes with diabetic macular edema and vitreomacular traction. Ophthalmology, Vol.117, No.6, (June 2010), pp. 1087-1093, ISSN 0161-6420

DRS 1979: Four risk factors for severe visual loss in diabetic retinopathy. DRS report 3. Diabetic Retinopathy Study Research Group. Archives of Ophthalmology, Vol.97, No.4, (April 1979), pp. 654-655, ISSN 0003-9950

DRS 1981: Photocoagulation treatment of proliferative diabetic retinopathy: clinical application of Diabetic Retinopathy Study (DRS) findings. DRS report 8. Diabetic Retinopathy Study Research Group. Ophthalmology,Vol.88,No.7, (July 1981), pp. 583-600, ISSN 0161-6420

DRVS 1985: Early vitrectomy for severe vitreous hemorrhage in diabetic retinopathy: twoyear results of a randomized trial. DRVS report 2. Diabetic Retinopathy Vitrectomy Study Research Group. Archives of Ophthalmology, Vol.103, No.11, (November 1985), pp. 1644-1652, ISSN 0003-9950

ETDRS 1991: Early photocoagulation for diabetic retinopathy. ETDRS report 9. Early Treatment Diabetic Retinopathy Study Research Group. Ophthalmology, Vol.98, No.5(suppl.), (May 1991), pp.766-785, ISSN 0161- 6420

ETDRS 1995: Focal photocoagulation treatment of diabetic macular edema: relationship of treatment effect to fluorescein angiographic and other retinal characteristics at baseline. ETDRS report 19. Early Treatment Diabetic Retinopathy Study Research Group. Archives of Ophthalmology, Vol.113, No.9, (September 1995), pp. 1144-1155, ISSN 0003-9950

Flynn HW \& Smiddy WE. (Eds.) (2000). Diabetes and ocular disease: past, present and future therapies. In: Ophthalmology Monograph 14, pp. 49-53, 266, American Academy of Ophthalmology, ISBN 1560551739, San Francisco, USA.

Gillies MC.; Sutter FK.; Simpson JM. et al. (2006). Intravitreal Triamcinolone for refractory diabetic macular edema: two-year results of a double-masked, placebo-controlled, randomized clinical trial. Ophthalmology, Vol.113,No.9, (September 2006), pp. 15331538, ISSN 0161-6420

Grover D.; Li TJ.; Chong CC. (2008). Intravitreal steroids for macular edema in diabetes. Cochrane Database Systematic Reviews, (January 2008), CD00565.54

Hauser D.; Katz H.; Pokroy R. et al. (2004). Occurrence and progression of diabetic retinopathy after phacoemulsification cataract surgery. Journal of Cataract and Refractive Surgery, Vol.30, No.2, (February 2004), pp.428-432, ISSN 0886-3350

Hayashi K.; Igrarashi C.; Hirata A. et al. (2009). Changes in diabetic macular edema after phacoemulsification surgery. Eye (London), Vol.23, No.2, (February 2009), pp. 386389, ISSN 0950-222X

Jaffe GJ.; Burton TC.; Kuhn E. et al. (1992). Progression of nonproliferative diabetic retinopathy and visual outcome after extracapsular cataract extraction and 
intraocular lens implantation. American Journal of Ophthalmology, Vol.114, No.4, (October 1992), pp. 448-456, ISSN 0002-9394

Kaiser Pk.; Riemann CD.; Sears JE.; Lewis H. (2001). Macular traction detachment and diabetic macular edema associated with posterior hyaloids traction. American Journal of Ophthalmology, Vol.131, No.1, (January 2001), pp.44-49, ISSN 00029394

Kastelan S.; Tomic M.; Pavan J.; Oreskovic S. (2010). Matrenal immune system adaptation to pregnancy- a potential influence on the course of diabetic retinopathy. Reproductive Biology and Endocrinology, Vol.8 (October 2010), pp. 124-128, ISSN 1477-7827

Klein R.; Knudtson MD.; Lee KF. et al. (2008). The Wisconsin Epidemiologic Study of Diabetic Retinopathy: XXII the twenty-five-year progression of retinopathy in persons with type 1 diabetes. Ophthalmology, Vol.115, No.11, (November 2008), pp. 1859-1868, ISSN 0161-6420

Kline LB.; Tariq-Bhatti M.; Chung SM. et al. (Eds.) (2010). Section 5: Neuro-ophthalmology. Basic and Clinical Science Course, 2010-2011, American Academy of Ophthalmology. American Academy of Ophthalmology, ISBN 9781615251339

Maia OO, Jr.; Takahashi BS.; Costa RA. et al. (2009). Combined laser and intravitreal Triamcinolone for proliferative diabetic retinopathy and macular edema: one year results of a randomized clinical trial. American Journal of Ophthalmology, Vol.147, No.2, (February 2009), pp. 291-297, ISSN 0002-9394

Michaelidis M.; Kalines A.; Hamilton RD. et al. (2010). A prospective randomized trial of intravitreal Bevacizumab or laser therapy in the management of diabetic macular edema (BOLT study) 12-month data: report 2. Ophthalmology, Vol.117, No.6, (June 2010), pp. 1078-1086, ISSN 0161-6420

Mirshahi A.; Roohipoor R.; Lashay A. et al. (2008). Bevacizumab- augmented retinal laser photocoagulation in proliferative diabetic retinopathy: a randomized doublemasked clinical trial. European Journal of Ophthalmology, Vol.18, No.2, (March-April 2008), pp. 263-269, ISSN 1120-6721

Moradian S.; Ahmadieh H.; Malihi M. et al. (2008). Intravitreal Bevacizumab in active progressive proliferative diabetic retinopathy. Graefe's Archive for Clinical and Experimental Ophthalmology, Vol.246, No.12, (December2008),pp. 1699-1705, ISSN 1435-702X

Nicholson BP. \& Schachat AP. (2010). A review of clinical trials of anti-VEGF agents for diabetic retinopathy. Graefe's Archive for Clinical and Experimental Ophthalmology, Vol.248, No.7, (July 2010), pp. 915-930, ISSN 1435-702X

Obrosova SS.; Chung SS.; Kador PF. (2010). Diabetic cataracts: mechanisms and management. Diabetes/Metabolism Research and Reviews, Vol.26, No.3, (March 2010), pp. 172-180, ISSN 1262-3636

Ostri C.; Lund-Andersen H.; Sander B. et al. (2010). Bilateral diabetic papillopathy and metabolic control. Ophthalmology, Vol.117, No.11, (November 2010), pp.2214-2217, ISSN 0161-6420 
Pollack A.; Dotan S.; Oliver M. (1991). Course of diabetic retinopathy following cataract surgery. British Journal of Ophthalmology, Vol.75, No.1, (January 1991), pp. 2-8, ISSN 0007-1161

Powers AC. (2008). Diabetes Mellitus. In: Harrison's Principles of Internal Medicine, Fauci AS., Brownwald E., Kasper DL. et al. (Eds.), Mcgraw-Hill. Retrieved from: http://www.accessmedicine.com

Purdy EP.; Bolling JP.; Di-Lorenzo AL. et al. (Eds.) (2010). Endocrine disorders. In: Section 1: Update on general medicine. Basic and Clinical Science Course 2010-2011, American Academy of Ophthalmology, pp. 189-205, American Academy of Ophthalmology, ISBN 9781615251292

Raab EL.; Aaby AA.; Bloom JN. et al. (Eds.) (2010). Vitreous and retinal diseases and disorders. In: section 6: Pediatric ophthalmology and strabismus. Basic and Clinical Science Course 2010-2011, American Academy of Ophthalmology, pp. 296-297, American Academy of Ophthalmology, ISBN 9781615251346

Rashid S. \& Young LH. (2010). Progression of diabetic retinopathy and maculopathy after phacoemulsification surgery. International Ophthalmology Clinics, Vol.50, No.1, (Winter 2010), pp. 155-166, ISSN 0020-8167

Regillo C.; Holekamp N.; Johnson MW. et al. (Eds.) (2010). Retinal vascular disease: Diabetic retinopathy. In: Section 12, Retina and vitreous. Basic and Clinical Science Course, 2010-2011, American Academy of Ophthalmology, pp. 109-132, American Academy of Ophthalmology, ISBN 9781615251407

Reidy JJ.; Bouchard CS.; Florakis GJ. et al. (Eds.) (2010). Metabolic disorders with corneal changes. In: Section 8: External disease and cornea. Basic and Clinical Science Course 2010-2011, American Academy of Ophthalmology, pp. 307-308, American Academy of Ophthalmology, ISBN9781615251360

Shah AS. \& Chen SH. (2010). Catract surgery and diabetes. Current Opinion in Ophthalmology, Vol.21, No.1, (January 2010), pp. 4-9, ISSN 1040-8738

Shultz KL.; Birnbaum AD.; Goldsteir DA. (2005). Ocular disease in pregnancy. Current Opinions in Ophthalmology, Vol.16, No.5, (October 2005), pp. 431-435, ISSN 10408738

Silva PS.; Sun JK.; Aiello LP. et al. (2009). Role of steroids in the management of diabetic macular edema and proliferative diabetic retinopathy. Seminars in Ophthalmology, Vol.24, No.2, (April 2009), pp. 93-99, ISSN 0882-0538

Stirban A.; Rosen P.; Tschoepe D. (2008). Complications of type 1 diabetes: new molecular findings. Mount Sinai Journal of Medicine, Vol.75, No.4, (August 2008), pp. 328-351, ISSN 1931-7581

Tarantola RM.; Folk JC.; Culver Boldt H.; Mahajan VB. (2010). Intravitreal Bevacizumab during pregnancy. Retina, Vol.30, No.9, (October 2010), pp. 1405-1411, ISSN 0275004X

Thomas D. \& Graham E. (2008). Ocular disorders associated with systemic disease. In: Vaughan \& Asbury's General Ophthalmology, Riordan-Eva P. \& Whitcher JP. (Eds.), Mcgraw- Hill. Retrieved from:

http://www.accessmedicine.com 
Varma R. (2008). From a population to patients: The Wisconsin Epidemiologic Study of Diabetic Retinopathy. Ophtahlmology, Vol.115, No.11, (November 2008), pp. 18571858, ISSN 0161-6420

Vestgaard M.; Ringholm L.; Laugesen CS. et al. (2010). Pregnancy- induced sightthreatening diabetic retinopathy in women with type 1 diabetes. Diabetic Medicine, Vol.27, No.4, (April 2010), pp.431-435, ISSN 1464-5491

Wasik A.; Song HF.; Grimes A.; Engelke C.; Thomas A. (2009). Bevacizumab in conjunction with panretinal photocoagulation for neovascular glaucoma. Optometry, Vol.80, No.5, (May 2009), pp. 243-248, ISSN 1529-1839

Yilmaz T.; Weaver CD.; Gallagher MJ. et al. (2009). Intravitreal Triamcinolone acetonide injection for treatment of refractory diabetic macular edema: a systematic review. Ophthalmology, Vol.116, No.5, (May 2009), pp. 902-911, ISSN 0161-6420 


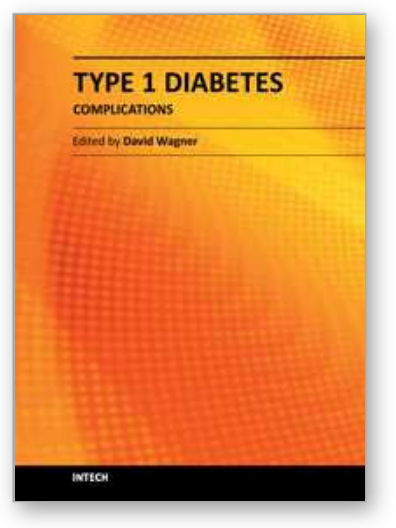

\author{
Type 1 Diabetes Complications \\ Edited by Prof. David Wagner
}

ISBN 978-953-307-788-8

Hard cover, 482 pages

Publisher InTech

Published online 25, November, 2011

Published in print edition November, 2011

This book is a compilation of reviews about the complication of Type 1 Diabetes. T1D is a classic autoimmune disease. Genetic factors are clearly determinant but cannot explain the rapid, even overwhelming expanse of this disease. Understanding etiology and pathogenesis of this disease is essential. The complications associated with T1D cover a range of clinical obstacles. A number of experts in the field have covered a range of topics for consideration that are applicable to researcher and clinician alike. This book provides apt descriptions of cutting edge technologies and applications in the ever going search for treatments and cure for diabetes.

\title{
How to reference
}

In order to correctly reference this scholarly work, feel free to copy and paste the following:

Daniel Rappoport, Yoel Greenwald, Ayala Pollack and Guy Kleinmann (2011). Ocular Complications of Type 1 Diabetes, Type 1 Diabetes Complications, Prof. David Wagner (Ed.), ISBN: 978-953-307-788-8, InTech, Available from: http://www.intechopen.com/books/type-1-diabetes-complications/ocular-complications-of-type1-diabetes

\section{INTECH}

open science | open minds

\section{InTech Europe}

University Campus STeP Ri Slavka Krautzeka 83/A 51000 Rijeka, Croatia Phone: +385 (51) 770447

Fax: +385 (51) 686166 www.intechopen.com

\section{InTech China}

Unit 405, Office Block, Hotel Equatorial Shanghai No.65, Yan An Road (West), Shanghai, 200040, China 中国上海市延安西路65号上海国际贵都大饭店办公楼 405 单元 Phone: +86-21-62489820

Fax: $+86-21-62489821$ 
(C) 2011 The Author(s). Licensee IntechOpen. This is an open access article distributed under the terms of the Creative Commons Attribution 3.0 License, which permits unrestricted use, distribution, and reproduction in any medium, provided the original work is properly cited. 